\title{
Expanding Our Students' Brainpower: Idea Generation and Critical Thinking Skills
}

\author{
Julie L. P. Jessop \\ University of Iowa
}

\begin{abstract}
How do we teach our students to think? This is not a skill that they can pick up by doing "X" number of homework problems; it is the product of good habits that must be practiced and honed on a daily basis. It is a state of mind that continually questions "Who? What? Where? When? How? Why?" In light of this reality, we developed this segment for the "Introduction to Literature Review and Proposal Writing" graduate course this past summer. Our goals during this three-day class period were:

- To define the creative process

- To identify techniques that enhance creativity

- To practice idea generation and critical thinking skills in controlled settings
\end{abstract}

This segment helps smooth the transition between the undergraduate mentality of "teach me" to the desired graduate student mentality of "enable me". It attempts to demystify the creative process, which most people associate with inspired moments and geniuses, so that students can deliberately foster an atmosphere that will help them generate new research ideas.

\section{Course History}

"Introduction to Literature Review and Proposal Writing" was first developed two years ago as a required core course for incoming chemical and biochemical engineering (CBE) graduate students. The course has been offered two summers with a CBE faculty member coordinating course content and projects. Various CBE faculty members delivered individual lectures, and a team of CBE faculty members graded student work.

This year, course delivery has been modified to increase instructional continuity by assigning it to one CBE faculty member who delivers the majority of class lectures. It has also been moved to the spring semester of the first year for incoming graduate students. In this way, the students will move into their first summer prepared to focus on their research projects without the distractions of coursework.

\section{Introduction}

New graduate students are often overwhelmed by the thought of developing innovative research ideas and writing a dissertation. Too often they are intimidated by the end product and do not realize that it is a process, not sheer luck or genius, that will lead them to their goals. Many students have developed bad habits that short circuit a healthy creative process and leave them 
dreading certain aspects of their educational experience. For example, instead of reviewing course material on a regular basis, which would promote better understanding and long-term retention, some students cram the night before exams. This type of behavior is also seen with writing assignments - students may wait to write a paper the night before it is due because "they work better under pressure." This "bingeing" behavior does not promote effective and efficient learning, and in fact, it creates a sense of anxiety in the student's mind when faced with these assignments because they associate the pain and suffering of these all-night sessions with them. In his book Advice for New Faculty Members, ${ }^{1}$ Robert Boice strongly argues against this bingeing behavior. Rather, he touts the motto nihil nimus (nothing in excess), which advocates working at tasks a little at a time, but in a continuous manner. It is this approach to the creative process-purposeful and on-going - that we strive to instill in our graduate students during this segment of the course. This paper provides an overview of the lectures, discussions and activities that comprise the coaching we give our students in idea generation and critical thinking during these classes.

\section{Defining Creativity}

The creative process is not a magical concept. It is simply the exercise of the higher-level skills listed in Bloom's taxonomy (see Table 1): analysis, synthesis and evaluation. Throughout their undergraduate education, students have spent much of their brainpower on the lower-level skills, which makes the transition to a critically thinking graduate student more challenging.

Table 1. Bloom's Taxonomy ${ }^{2}$

\begin{tabular}{|l|l|}
\hline \multicolumn{2}{|c|}{ Lower-level skills } \\
\hline Knowledge & Finding out \\
\hline Comprehension & Understanding \\
\hline Application & Making use of knowledge \\
\hline & Higher-level skills \\
\hline Analysis & Taking apart the known \\
\hline Synthesis & Putting things together in another way \\
\hline Evaluation & Judging outcomes \\
\hline
\end{tabular}

That these higher-level skills are pivotal to successful idea generation is reiterated by the following definition of critical thinking:

Critical thinking is the intellectually disciplined process of actively and skillfully conceptualizing, applying, analyzing, synthesizing, and/or evaluating information gathered from, or generated by, observation, experience, reflection, reasoning, or communication, as a guide to belief and action. ${ }^{3}$

Thus, critical thinking paves the pathway of the creative process. The higher-level thinking skills are not innate or instantaneous, but must be practiced and honed on a continual basis. Students must realize that this is a life-long learning process that requires discipline of thought and cannot be achieved in a moment of inspiration or mastered at any given time. 
Exercising critical thinking must be done in a deliberate manner. This includes fostering an atmosphere for creativity and participating in activities that use the higher-level thinking skills. There are numerous ways to promote creativity in students: listening to classical music, taking walks, recording all ideas down in a notebook, holding debates, etc. ${ }^{4}$ In the "Introduction to Literature Review and Proposal Writing" course, we focus on two specific activities: brainstorming and critical reading.

\section{Brainstorming}

Linus Pauling, the recipient of two Nobel prizes, stated that "the best way to get a good idea is to get a lot of ideas." In other words, for every great idea brought forth, there will be many others preceding it that were less than stellar. In brainstorming, participants generate enough ideas so that the probability that one or more idea is viable increases. The quality and quantity of the brainstorming session may vary according to the number of participants (see Table 2). For example, if an individual were brainstorming, the ideas generated would not be very developed because there is a limit to the depth of their knowledge. To contrast, in group brainstorming, the ideas could be more fully developed because what one person in the group does not know, another might.

Table 2. Brainstorming-Alone or Together? ${ }^{6}$

\begin{tabular}{|l|c|c|}
\hline & Individual & Group \\
\hline Range of ideas & Wide & Narrow \\
\hline Development of ideas & Shallow & Deep \\
\hline Freedom of expression & More & Less \\
\hline
\end{tabular}

There are numerous suggestions for organizing a brainstorming session, including rules on the recording and reception of ideas in a group setting. ${ }^{7-12}$ However, the basic format can be broken down as follows: ${ }^{12}$

1. Discuss the problem

2. Think about how to solve it

3. Screen the contributions

4. Commit to action

The first step is the key to generating great ideas: identification and clarification of the problem. John Dewey, the philosopher, commented that "a problem well-stated is a problem half-solved.", William Deming, the quality-control expert, echoed that sentiment when relaying the following:

When asked what single event was most helpful in developing the Theory of Relativity, Albert Einstein replied, "Figuring out how to think about the problem.",

Thus, becoming familiar with the critical issues in an area or spending time developing the physical picture of the system will speed the generation of new research ideas. In essence, by clearly viewing the problem from all angles, it is easier to start the brainstorming process. It is also imperative when brainstorming in a group that all members understand the question to be 
answered before suggesting solutions (i.e., they are all on the same page). If some group members misinterpret the problem, they will not be contributing to the solution, and they may slow down the brainstorming process.

The second step is the actual brainstorming for solutions or ideas. It involves collecting as many ideas as possible and building upon one another's ideas (in group brainstorming) to generate even more ideas. Judgment of these ideas is reserved for the third step. Only at this time are similar ideas combined, criteria for judging the ideas determined, and the best ideas chosen. The final step involves acting upon the best ideas and evaluating the results (e.g., run the experiment and determine if the hypothesis was proven or not).

In this course, students are given practice brainstorming individually and as a group. After discussing how to brainstorm effectively in class, the students are assigned one of two topics: new uses for agricultural oils or methods for removing/reducing greenhouse gases in the earth's atmosphere. They are then asked to gather information on the subject (clarify the problem), which they will brainstorm during the next two class periods. This brainstorming session leads the students through a series of exercises that alternates among individual, small group (two students) and large group (all students) brainstorming to compare the quality and quantity of ideas gathered. Finally, the small groups develop a "business proposal" for their best solution and present it to the entire class. The class votes upon the viability of each proposal to determine what plan would most likely be funded and implemented.

\section{Critical Reading}

The philosopher John Locke said "reading furnishes the mind only with materials of knowledge; it is thinking that makes what we read ours." ${ }^{3}$ Reading provides the fodder for idea generation; however, creativity is not fostered by simply reading, but by critically reading. The key difference is in the attitude of the reader: a critical thinker asks questions while reading and does not take what is written for granted or accept it at face value. True critical reading requires asking questions that invoke the entire spectrum of Bloom's Taxonomy (see Table 3).

Table 3. Thinking skills used while reading critically

\begin{tabular}{|l|l|l|}
\hline Reading Activity & \multicolumn{1}{|c|}{ Bloom's Taxonomy } & \multicolumn{1}{|c|}{ Examples of Questions } \\
\hline Summarize/define & $\begin{array}{l}\text { Knowledge } \\
\text { Comprehension }\end{array}$ & $\begin{array}{l}\text { What is...? } \\
\text { What is an example of...? }\end{array}$ \\
\hline Analyze & Analysis & $\begin{array}{l}\text { How...? } \\
\text { What are the reasons for...? }\end{array}$ \\
\hline Hypothesize & $\begin{array}{l}\text { Application } \\
\text { Synthesis }\end{array}$ & $\begin{array}{l}\text { What would happen if...? } \\
\text { If this happened, what would be different? }\end{array}$ \\
\hline Evaluate & Evaluation & $\begin{array}{l}\text { Proven or not proven? } \\
\text { What are the pros or cons of...? }\end{array}$ \\
\hline
\end{tabular}

Most students have no problem with summarizing what they read, but this activity is merely a lower-level thinking skill. By encouraging students to read using the higher-level skills (analysis, synthesis and evaluation), the wheels of the creative process begin to turn. They start to see holes in the work where further investigation is needed, faulty arguments or unfounded 
claims that open up new possibilities for research-they can conceive ideas that will extend in new directions and meet a need in that area. Several authors have suggested specific questions readers should ask when critiquing scientific articles; ${ }^{15-16}$ many of these questions are summarized in the following list suggested by Seals and Tanaka: ${ }^{17}$

- Is the experimental question significant?

- Is a clear and testable hypothesis presented?

- Is the overall experimental approach valid?

- Are the results properly presented and believable?

- Are the conclusions reasonable on the basis of the results obtained?

- Are the major findings both novel and important?

Since students may find the first and last questions difficult to evaluate, it is important to describe the qualities entailed in a good idea. An excellent framework for this discussion is the review criteria found in the NSF Grant Proposal Guide. ${ }^{18}$ In this case, reviewers are asked to evaluate the intellectual merit (novelty) and the broader impacts (significance and importance) of the research. The definitions of these attributes are summarized in Table 4 below.

Table 4. What makes a good idea? ${ }^{18}$

\begin{tabular}{|c|c|}
\hline Intellectual merit & $\begin{array}{l}\text { - } \quad \text { New knowledge and understanding } \\
\text { - Creative and original concepts } \\
\text { - } \quad \text { Well conceived and organized plan }\end{array}$ \\
\hline Broader impacts & $\begin{array}{l}\text { - } \text { Teaching, training and learning } \\
\text { - Underrepresented groups } \\
\text { - Scientific community } \\
\text { - Society }\end{array}$ \\
\hline
\end{tabular}

With this framework, students can develop a tangible method to judge the journal articles they read. In addition, they are made aware of the yardstick others will use to measure their proposals and papers.

In this course, students are given practice reading critically several journal articles in their research area, some of which may be suggested by their advisors. After discussing how to critique scientific manuscripts in class, the students are assigned a literature review on their research topic. They choose 10 articles and summarize their content. They then select the four best papers and the weakest paper to review critically: they must point out the strengths and weaknesses of the research and discuss how this research impacts their project. These reviews are distributed to a panel of three professors (including their advisor) for grading and feedback, as well as given as oral presentations in class. Based upon the comments from their fellow classmates and the review panel, students revise and expand the literature summary and incorporate it into a research proposal, which is the final course project.

\section{Segment Evaluation}

In the brainstorming segment, we have found that the students generate more ideas if the facilitator asks a series of questions on the first day to "prime the pump." The students leave that 
first session to research the topic and return with fresh ideas based on the answers they found. We have also adopted the guideline that each student must provide an answer to every question. To increase the pace of discussion and ensure that the students can meet this guideline, the students individually write three to five answers to a question on a note card and then share one idea with the larger group. This process is repeated a second time with the same question to get "springboard" ideas before moving on to the next question. The quality of the session is evaluated by the number and originality of the ideas. Records of the brainstorming results from the last year's class are used as a challenge to the current class (e.g., can they come up with more ideas than the previous class did?). As a result of this experience, a greater percentage of the students participates fully in discussions and brainstorming sessions of subsequent lectures.

In response to the critical reading assignment, the students' literature reviews are typically superficial at first, and they fail to examine the methods, results and discussions in papers closely enough to identify true strengths and weaknesses. When the faculty panel challenges their analyses, the students must rewrite their reviews to address the noted deficiencies. Although they do not achieve "expert" status during this course, their summaries and critiques show a marked improvement from the first assignment to its incorporation in the final research proposal submitted for the course. Future modifications of this segment will include providing students with anonymous excerpts of reviews from previous years (good and bad), as well as an in-class exercise in analyzing a short research paper.

\section{Conclusion}

In this segment of "Introduction to Literature Review and Proposal Writing," we define creativity as the application of critical thinking skills (analysis, synthesis and evaluation). Developing these skills is a life-long practice that must be deliberately pursued. During the course, graduate students practice two methods to enhance their creativity: brainstorming and critical reading. These activities are designed to help them begin generating research ideas and developing their research proposal for their graduate studies.

1. Boice, R. (2000). Advice for New Faculty Members: Nihil Nimus. Boston: Allyn and Bacon.

2. Kent School District (2001). Teaching Using Bloom's Taxonomy. Retrieved January 2, 2002, from the World Wide Web: http://www.kent.wednet.edu/KSD/MA/resources/blooms/teachers_blooms.html.

3. Scriven, M., \& Paul, R. Defining Critical Thinking. Retrieved January 2, 2002, from the World Wide Web: http://www.criticalthinking.org/university/univclass/Defining.html.

4. Baumgartner, J. (1996). 10 Steps for Boosting Creativity. Retrieved January 2, 2002, from the World Wide Web: http://www.jpb.com/creative/creative.html.

5. Cave, C. (2001). Creativity Web: Resources for Creativity and Innovation. Retrieved January 2, 2002, from the World Wide Web: http://members.ozemail.com.au/ caveman/Creative/index2.html.

6. Mind Tools (2002). Brainstorming. Retrieved January 2, 2002, from the World Wide Web: http://www.mindtools.com/brainstm.html.

7. Levine, A. (2001). Brainstorming. Retrieved January 2, 2002, from the World Wide Web: http://www.mcli.dist.maricopa.edu/authoring/studio/guidebook/brain.html. 
8. Guffey, M.E. (1998). Five Step to Better Critical-thinking, Problem-solving, and Decision-making Skills. Retrieved January 2, 2002, from the World Wide Web: http://www.westwords.com/GUFFEY/critical.html.

9. Baumbartner, J. (1997). The Step-by-step Guide to Brainstorming. Retrieved January 2, 2002, from the World Wide Web: http://www.jpb.com/creative/brainstorming.html.

10. Bennett, B. (1991). Brainstorming. The Chemical Engineer, 492, 40-42.

11. Gamache, R., \& Eastman, K.W. (1990). Running a Creative Meeting. Chemical Engineering, 97(11), 165-174.

12. Kling, H. (1990). Get More Out of Group Projects by Using Structured Brainstorming. Quality Progess, 23(3), 136.

13. Baertracks (2001). Creative Quotations. Retrieved January 2, 2002, from the World Wide Web: http://www.creativequotations.com/.

14. Counselling and Development Centre (2001). Reading Skills for University: 4. Critical Thinking. Retrieved January 2, 2002, from the World Wide Web: http://www.yorku.ca/admin/cdc/lsp/read/read4.htm.

15. Fogler, H.S. (1992). Elements of Chemical Reaction Engineering ( $2^{\text {nd }}$ ed.). New Jersey: Prentice Hall.

16. Brunette, D.M. (1996). Critical Thinking: Understanding and Evaluating Dental Research. Chicago: Quintessence Publishing Co., Inc.

17. Seals, D.R., \& Tanaka, H. (2000). Manuscript Peer Review: A Helpful Checklist for Students and Novice Referees. Advances in Physiology Education, 23(1), 52-58.

18. National Science Foundation (2002). Grant Proposal Guide, NSF 02-2. Retrieved January 2, 2002, from the World Wide Web: http://www.nsf.gov/pubs/2002/nsf022/nsf022.pdf.

\section{JULIE L. P. JESSOP}

Julie Jessop is an Assistant Professor of Chemical and Biochemical Engineering at the University of Iowa. She is actively involved in polymer research and teaches a series of polymer courses in addition to the "Introduction to Literature Review and Proposal Writing" course. She received her Ph.D. in chemical engineering from Michigan State University. 